\title{
Role of Magnetic Resonance Imaging in evaluation of adult non-traumatic painful hip
}

\author{
Noha M. Osman, Tarek W. Hemeda, Mariam T. Thabit \\ Department of Radiodiagnosis, Faculty of Medicine, Ain Shams University
}

\begin{abstract}
Aim of the Work: to assess the role of Magnetic Resonance Imaging as a non-invasive diagnostic modality in adult patients with non-traumatic painful hip joint.

Patients and Methods: This study was conducted on 60 adult patients with non-traumatic hip pain, referred from the outpatient orthopedic clinic, Ain Shams University hospitals. The patients were investigated using magnetic resonance imaging (MRI). All MR imaging examinations were conducted at the Department of Radiodiagnosis of the Ain shams University with the same 1.5-T unit (Philips Healthcare, Best, the Netherlands) with a body coil.

Results: avascular necrosis is the commonest cause of bilateral hip pain (25\%) of the study patients followed by osteoarthritis $(11.7 \%)$, while unilateral hip pain is commonly caused by stress fractures $(8.3 \%)$, isolated joint effusion (10\%) and tendinopathies (3.3\%). Other causes included Marrow edema with hip effusion, chronic anemic state, migratory osteoporosis, osteoid osteoma, bursitis, bone infarcts, osseous hemangioma, hemosiderosis, sacroiliitis, femoral-acetabular impingement, iliacus abscess and bone marrow edema. Magnetic resonance imaging doesn't only demonstrate disorders of hip joint only; it also gives an accurate assessment of other extra-articular causes of referred hip pain as degenerative disc diseases and pelvic conditions.

Conclusion: Magnetic resonance is the best imaging modality to assess hip joint in nontraumatic cases. It has a great ability to diagnose disorders of bone, cartilage, ligaments, muscles and soft tissue. MRI can also detect joint effusion and bone marrow edema.

Key words: Magnetic Resonance Imaging, adult non-traumatic painful hip, non-invasive diagnostic modality
\end{abstract}

\section{Introduction}

Hip joint is a major weight-bearing joint with significant mobility. Hip pain in non-traumatic cases is a non-specific symptom occurring in $14 \%$ of the population over 60-year age ${ }^{(1)}$. There are different etiologies for hip pain either articular or extra-articular ${ }^{(2)}$.

In adults, intraarticular causes may include avascular necrosis, arthritis, loose bodies, tendonitis and bursitis, while extra-articular causes may include referred pain from lumbar spine, sacroiliac joint and nerve entrapment syndromes ${ }^{(3)}$.

Normal appearing radiographs, nonreliable history and clinical findings forms a difficult diagnostic dilemma. Many conditions as trauma, infection, arthritis, avascular necrosis, tumor, and hip dysplasia can manifest with non- significant radiographic findings ${ }^{(4)}$.Here comes the importance of Magnetic

Resonance as a non-invasive diagnostic imaging modality for characterizing hip anatomy and pathology. Magnetic resonance imaging (MRI) advantage is helping in accurately detection, localization, and characterization of hip pathology, which leads to improve diagnosis and proper managing of

different intra-articular and extraarticular pathologies of hip pain ${ }^{(5)},{ }^{(6)}$.

\section{Aim of work}

The purpose of our study is to assess the role of Magnetic Resonance Imaging as a non-invasive diagnostic modality in adult patients with non-traumatic painful hip joint.

\section{Patients and Methods}


This study is conducted on adult patients with non-traumatic hip pain, referred from the outpatient orthopedic clinic, Ain Shams University hospitals. The patients were investigated using magnetic resonance imaging (MRI).

Study place:Ain Shams University Hospitals -Cairo-Egypt.

Sample size: 60 patients

Equipment used: All MR imaging examinations were conducted at the Department of Radiodiagnosis of the Ain shams University with the same 1.5$\mathrm{T}$ unit (Philips Healthcare, Best, the Netherlands) with a body coil.

\section{Inclusion criteria:}

A.Age group: adult age (between 18 and 80 years).

B.Both sexes were included.

C.patients with unilateral or bilateral painful hip joint who underwent hip MRI.

\section{Exclusion criteria:}

Patients with history of trauma and younger than 18 years were excluded from the study.

MRI protocol including the following:

1. All MR imaging examinations were conducted at the Department of Radiodiagnosis of the Ain shams University with the same 1.5-T unit (Philips Healthcare, Best, the Netherlands) with a body coil.
2. The images of the selected patients were obtained:

.coronal T1 TSE $(\mathrm{TR}=1106, \mathrm{TE}=24$, $\mathrm{FOV}=39.3 \times 37.7 \mathrm{Cm}$, slice thickness $4 \mathrm{~mm})$.

.coronal T2 TSE (TR=3500, TE=120, $\mathrm{FOV}=39.3 \times 37.7 \mathrm{~cm}$, slice thickness $4 \mathrm{~mm})$, coronal T2 FFE (TR=682.9, $\mathrm{TE}=18.4, \quad \mathrm{FOV}=39.3 \times 37.7 \mathrm{Cm}, \quad$ slice thickness 4mm).

.coronal STIR TSE $(\mathrm{TR}=2656.8, \mathrm{TE}=55$, $\mathrm{FOV}=39.3 \times 37.7 \mathrm{~cm}$, slice thickness $4 \mathrm{~mm})$.

.axial T1 TSE $(\mathrm{TR}=1363.8, \quad \mathrm{TE}=24$, $\mathrm{FOV}=36.8 \times 38.6 \mathrm{~cm}$, slice thickness $4 \mathrm{~mm})$.

.axial T2 TSE $(\mathrm{TR}=3500, \mathrm{TE}=110$, $\mathrm{FOV}=36.8 \times 38.6 \mathrm{~cm}$, slice thickness $4 \mathrm{~mm})$.

.axial STIR TSE $(\mathrm{TR}=3600, \mathrm{TE}=30$, $\mathrm{FOV}=36.8 \times 38.6 \mathrm{~cm}$, slice thickness $4 \mathrm{~mm})$.

Contrast administration of Gadolinium injection $0.1 \mathrm{~mL} / \mathrm{kg}$ body weight $(0.1 \mathrm{mmol} / \mathrm{kg})$, was given intravenous to selected cases according to clinical suspicion.

\section{Images Interpretation:}

MRI images were reviewed by musculoskeletal radiologists in the radiodiagnosis department using the different sequences and planes to assess the findings.

\section{Results}

\section{1-Demographic data:}

The study included 60 patients, females 41 (68.3\%) and males 19(31.7\%) (table 6). The mean age group was 20-40 years with 6 patients under the age of 20 years old (10\%), 31 patients between the ages of 20 to 40 years old (51.7\%), 14 patients between the ages of 40 to 60 years old (23.3\%), 9 patients between the age of 60 to 80 years old (15\%) (table 7).

2- Clinical Data:-

All of the 60 cases (100\%) complained of pain in one or both hip joints whereas none of them $(0 \%)$ had history of trauma.

\section{3- MRI Data:}

Out of 60 patients, 18 patients (30\%) had unilateral abnormalities in MR images and 32 patients (53.3\%) had bilateral hip joint abnormalities, while 10 cases (16.7\%) showed no MRI signs of any disease (table 1). 
SOHAG MEDICAL JOURNAL

Vol. 23 No.2Apr 2019
Role of Magnetic Resonance Imaging

Mariam T. Thabit.et al

\begin{tabular}{|l|l|l|}
\hline & number & Percentage \\
\hline Unilateral & 18 & $30 \%$ \\
\hline Bilateral & 32 & $53.3 \%$ \\
\hline normal & 10 & $16.7 \%$ \\
\hline total & 60 & $100 \%$ \\
\hline
\end{tabular}

Table (1): laterality of MRI abnormal findings.

MRI images of the 60 patients examined revealed the following results as final main diagnoses:

Out of 60 cases, 15 cases (25\%) were diagnosed as Avascular necrosis, 7 cases $(11.7 \%)$ as osteoarthritis, 6 cases $(10 \%)$ as isolated hip joint effusion, 5 cases $(8.3 \%)$ as stress fracture, 3 cases (5\%) as combined bone marrow edema with hip effusion, 2 cases $(3.3 \%)$ as tendinopathy, 2 cases $(3.3 \%)$ as chronic state of illness likely chronic anemic state, 1 cases (1.67\%) as migratory osteoporosis, 1 case $(1.67 \%)$ as simple ovarian cyst, 1 case $(1.67 \%)$ as bursitis, 1 case (1.67\%) as multiple bone infarcts, 1 case $(1.67 \%)$ as hemorrhagic ovarian cyst, 1 case $(1.67 \%)$ as hemosiderosis, 1 case $(1.67 \%)$ as sacroiliitis, 1 case $(1.67 \%)$ as femoral-acetabular impingement, 1 case $(1.67 \%)$ as iliacus abscess, 1 case $(1.67 \%)$ as femoral neck bone marrow edema only, 10 cases $(16.7 \%)$ were found to be normal (table 2$)$.

\begin{tabular}{|c|c|c|}
\hline Condition & number & percentage \\
\hline Avascular necrosis & 15 & $25 \%$ \\
\hline osteoarthritis & 7 & $11.7 \%$ \\
\hline $\begin{array}{lll}\begin{array}{l}\text { Isolated } \\
\text { effusion }\end{array} & \text { Hip } & \text { joint } \\
\end{array}$ & 6 & $10 \%$ \\
\hline Stress fracture & 5 & $8.3 \%$ \\
\hline $\begin{array}{l}\text { Marrow edema with } \\
\text { hip effusion }\end{array}$ & 3 & $5 \%$ \\
\hline tendinopathy & 2 & $3.3 \%$ \\
\hline Chronic anemic state & 2 & $3.3 \%$ \\
\hline $\begin{array}{l}\text { Migratory } \\
\text { osteoporosis }\end{array}$ & 1 & $1.67 \%$ \\
\hline $\begin{array}{l}\text { Simple large ovarian } \\
\text { cyst }\end{array}$ & 1 & $1.67 \%$ \\
\hline Bursitis & 1 & $1.67 \%$ \\
\hline Bone infarcts & 1 & $1.67 \%$ \\
\hline $\begin{array}{l}\text { Hemorrhagic ovarian } \\
\text { cyst }\end{array}$ & 1 & $1.67 \%$ \\
\hline hemosiderosis & 1 & $1.67 \%$ \\
\hline Sacroiliitis & 1 & $1.67 \%$ \\
\hline $\begin{array}{l}\text { Femoral-acetabular } \\
\text { impingement }\end{array}$ & 1 & $1.67 \%$ \\
\hline Iliacus abscess & 1 & $1.67 \%$ \\
\hline $\begin{array}{l}\text { Femoral head bone } \\
\text { marrow edema }\end{array}$ & 1 & $1.67 \%$ \\
\hline Normal both hips & 10 & $16.7 \%$ \\
\hline Total & 60 & $100 \%$ \\
\hline
\end{tabular}

Table (2): distribution of the main pathologies causing hip pain diagnosed by MRI in total 60 patients. 
SOHAG MEDICAL JOURNAL

Vol. 23 No.2Apr 2019
Role of Magnetic Resonance Imaging

Mariam T. Thabit.et al

However, there were combined multiple secondary diagnoses as some single cases showed a variety of findings interpreted as below (table 3 ).

\begin{tabular}{|l|l|l|}
\hline condition & number & percentage \\
\hline Avascular necrosis & 15 & $25 \%$ \\
\hline osteoarthritis & 11 & $18.4 \%$ \\
\hline Stress fracture & 6 & $10 \%$ \\
\hline tendinopathy & 3 & $5 \%$ \\
\hline Chronic anemic state & 2 & $3.3 \%$ \\
\hline $\begin{array}{l}\text { Migratory } \\
\text { osteoporosis }\end{array}$ & 1 & $1.67 \%$ \\
\hline Osteoid osteoma & 1 & $1.67 \%$ \\
\hline Bursitis & 2 & $3.3 \%$ \\
\hline Bone infarcts & 1 & $1.67 \%$ \\
\hline Osseous hemangioma & 1 & $1.67 \%$ \\
\hline hemosiderosis & 1 & $1.67 \%$ \\
\hline Sacroiliitis & 2 & $3.3 \%$ \\
\hline $\begin{array}{l}\text { Femoral-acetabular } \\
\text { impingement }\end{array}$ & 1 & $1.67 \%$ \\
\hline Iliacus abscess & 1 & $1.67 \%$ \\
\hline Bone marrow edema & 19 & $31.7 \%$ \\
\hline Hip joint effusion & 24 & $40 \%$ \\
\hline Bony islands & 1 & $1.67 \%$ \\
\hline Bone cysts & 1 & $1.67 \%$ \\
\hline Muscle pathology & 3 & $5 \%$ \\
\hline Osteoporosis & 2 & $3.3 \%$ \\
\hline Pelvic ascites & 1 & $1.67 \%$ \\
\hline Synovitis & 2 & $3.3 \%$ \\
\hline Simple ovarian cyst & 2 & $3.3 \%$ \\
\hline $\begin{array}{l}\text { Hemorrhagic ovarian } \\
\text { cyst }\end{array}$ & 1 & $1.67 \%$ \\
\hline Normal both hips & 10 & $16.7 \%$ \\
\hline total & 114 & $190 \%$ \\
\hline (3) cetails of abnorma & 1 & \\
\hline
\end{tabular}

Table (3): details of abnormal MRI findings as demonstrated in total 60 MRI.

Our study proved that avascular necrosis and osteoarthritis are the most common causes of non-traumatic painful hip joint.

There were specific MRI findings of each of the two diseases. Most cases showed one or more signs.

In all cases of avascular necrosis, focal subchondral sign abnormalities were noted, double line sign in $80 \%$, joint effusion in $66.7 \%$, marrow edema in $60 \%$, collapsed deformed femoral head in $20 \%$ of the cases (table 4 ).

\begin{tabular}{|l|l|l|}
\hline MRI findings & Number & Percentage \\
\hline $\begin{array}{l}\text { Focal subchondral sign } \\
\text { abnormality }\end{array}$ & 15 & $100 \%$ \\
\hline Double line sign & 12 & $80 \%$ \\
\hline Joint effusion & 10 & $66.7 \%$ \\
\hline Marrow edema & 9 & $60 \%$ \\
\hline $\begin{array}{l}\text { Collapsed deformed } \\
\text { femoral head }\end{array}$ & 3 & $20 \%$ \\
\hline
\end{tabular}

Table (4): diagnostic MRI findings seen in cases of avascular necrosis. 
In cases of osteoarthritis, all cases showed joint effusion, joint space narrowing and marginal osteophytes. Subchondral cysts were noted in $85.6 \%$, marrow edema in $42.9 \%$, synovial thickening in $14.3 \%$, and soft tissue edema in $14.3 \%$ (table 5).

\begin{tabular}{|l|l|l|}
\hline MRI finding & Number & Percentage \\
\hline Joint effusion & 7 & $100 \%$ \\
\hline $\begin{array}{l}\text { Joint space } \\
\text { narrowing }\end{array}$ & 7 & $100 \%$ \\
\hline $\begin{array}{l}\text { Marginal } \\
\text { osteophytes }\end{array}$ & 7 & $100 \%$ \\
\hline $\begin{array}{l}\text { Subchondral } \\
\text { cysts }\end{array}$ & 6 & $85.6 \%$ \\
\hline Marrow edema & 3 & $42.9 \%$ \\
\hline $\begin{array}{l}\text { Synovial } \\
\text { thickening }\end{array}$ & 1 & $14.3 \%$ \\
\hline $\begin{array}{l}\text { Soft tissue } \\
\text { edema }\end{array}$ & 1 & $14.3 \%$ \\
\hline
\end{tabular}

Table (5): diagnostic MRI findings seen in cases of osteoarthritis.

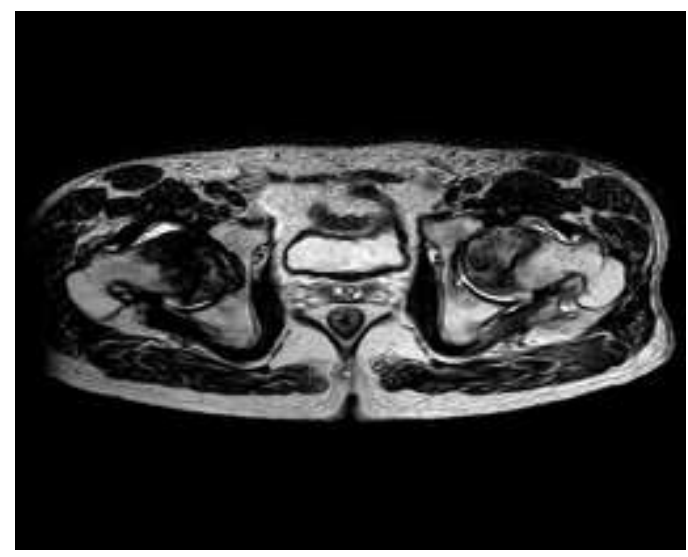

Figure (1): axial T2WI MRI show right femoral head low signal intensity and left femoral head heterogenous signal with double line sign in male patient 55 years old with history of bilateral hip joints and low back pain for years, denoting right grade D and left grade $\mathrm{C}$ avascular necrosis.

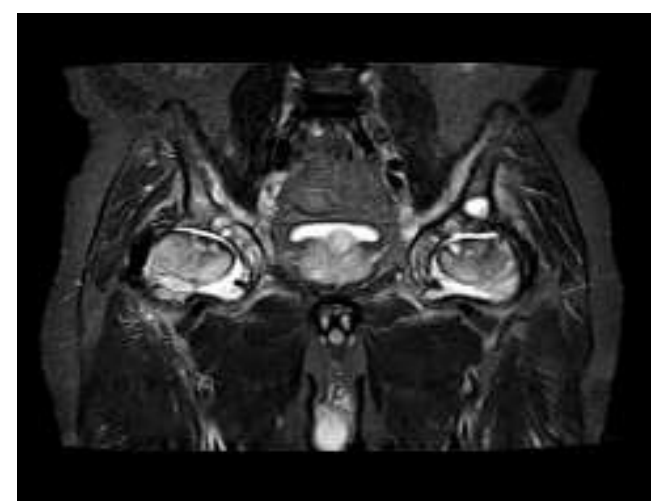

Figure (2): coronal T2W MRI showing loss of spherical contour of both femoral heads, narrow joint space, osteophytic lipping, synovial thickening and subchondral 
cystic changes at both joints in male patient 62 years old with history of bilateral hip joints and low back pain with inability to walk, denoting bilateral osteoarthritis.

\section{Discussion}

Magnetic resonance imaging is having a great role in musculoskeletal disorders as a non-invasive tool due to its multi-planar acquisition capability, excellent soft tissue resolution and nonionizing radiation ${ }^{(7)}$.

This retrospective study performed at Ain shams university hospitals was aiming to assess the role of magnetic resonance imaging as a non-invasive diagnostic tool in cases of non-traumatic painful hip joint in adults. The study included 60 cases of patients complaining of unilateral or bilateral hip pain in adult age group with exclusion of those who had history of trauma.

Both sexes were included in this study with different age groups. The mean age group was 20-40 years.

The study revealed that hip pain can be resulted by a wide spectrum of different etiologies. Avascular necrosis was the most common cause followed by osteoarthritis and isolated hip joint effusion.

Reddy ${ }^{(2)}$ in his study reported that the most common causes of unilateral hip pain were avascular necrosis and infection, and the most common causes of bilateral hip pain were avascular necrosis and osteoarthritis. Same

observation was made in this study that avascular necrosis and osteoarthritis are the most common causes of bilateral hip pain. However, our study revealed that stress fractures and isolated hip joint effusion and tendinopathy were the most common causes of unilateral hip pain.

In this study, 15 cases $(25 \%)$ were diagnosed with AVN, 2 of them were unilateral and 13 cases had bilateral

AVN. It was reported by Horia ${ }^{(8)}$ that MRI is the most sensitive imaging

modality used to diagnose AVN, representing the gold-standard of noninvasive diagnostic evaluation.

According to Boehm and Link ${ }^{(9)}$, the T1, T2 and STIR were the used sequences to diagnose AVN. The early stage shows high intensity signal on both T1 \& T2 WI, because of hyperaemia. On late stage, low signal intensity is seen on both T1 \& T2 WI as a result of sclerosis.

Tushar and Pooja ${ }^{(\mathbf{1 0})}$, in their study mentioned that $87 \%$ of AVN cases were noted to have bone marrow edema and $79 \%$ showed a characteristic specific finding of "double line " sign on T2 weighted images which consists of concentric low- and high signal intensity rims that surround the area of bone marrow signal intensity change within the femoral head. Joint effusion was noted in $62 \%$ in AVN cases.

In our study the double line sign was seen in 12 cases (80\%), bone marrow edema was seen at 9 cases $(60 \%)$, joint effusion was seen at 10 cases $(66.7 \%)$ of the AVN cases. 3 cases $(20 \%)$ were noted to have collapsed deformed femoral head.

In MRI images OA could be presented as loss of articular cartilage, joint space reduction, Joint effusion, Synovial thickening, Marrow edema, Subchondral cysts, Marginal osteophytes and Soft tissue edema. T1, T2 \& STIR WIs were sequences used for diagnosis. David et al ${ }^{(\mathbf{1 1})}$ mentioned that TI, T2, fat suppressed T2 weighted fast spin-echo and STIR are the sequences that are used to detect the early changes of OA.

The attenuation of articular cartilage is well demonstrated on either sagittal or coronal fat suppressed T2 images. OA 
SOHAG MEDICAL JOURNAL

Vol. 23 No.2Apr 2019
Role of Magnetic Resonance Imaging

Mariam T. Thabit.et al can also be accompanied with or on top of osteonecrosis of the femoral head.

Hayam ${ }^{(12)}$, in her study reported that $100 \%$ of osteoarthritis cases showed joint effusion, $70 \%$ had synovial thickening, $70 \%$ had bone marrow edema, $50 \%$ had subchondral cysts, $40 \%$ had joint space narrowing, $40 \%$ had marginal osteophytes and $30 \%$ had soft tissue edema.

In our study, 7 cases $(11.7 \%)$ were diagnosed as osteoarthritis. One of them was unilateral and 6 cases were bilateral. All the 7 cases $100 \%$ had Joint effusion, all the 7 cases $(100 \%)$ had joint space narrowing, all the 7 cases $(100 \%)$ had marginal osteophytes, 6 cases $(85.6 \%)$ had subchondral cysts, 3 cases $(42.9 \%)$ had bone marrow edema, 1 case $(14.3 \%)$ had synovial thickening, and 1 case (14.3\%) had soft tissue edema.

According to Tushar ${ }^{(10)}$, Findings of hip joint effusion on MRI were T2W and STIR high signal intensity within the joint space. MRI is the best modality to assess the amount of fluid minimal, moderate or severe.

In our study 6 cases (10\%) were diagnosed as isolated hip joint effusion, 3 cases were unilateral and 3 cases were bilateral.

Reddy ${ }^{(2)}$ mentioned that the diagnostic features of stress fractures in MRI images included linear low signal intensity in femoral neck (on all sequences) with surrounding bone marrow edema.

According to Quinn and Carthy ${ }^{(13)}$, Magnetic resonance imaging can early detect and diagnose stress fracture as it is presented with bone marrow edema best detected on fat-suppressed T2weighted or (STIR) sequences, the presence of medullary edema or hemorrhage appear as high signal intensity in a dark background of suppressed marrow fat. However, the low signal intensity line of fracture itself is not always seen.
In our study there were 5 cases $(8.3 \%)$ diagnosed as stress fracture. 4 of them were unilateral and one case had bilateral fractures.

Our study also took non-hip causes of referred hip pain in consideration. Four cases had extra hip causes of unilateral or bilateral hip pain, one case showed large simple ovarian cyst, one case had a hemorrhagic ovarian cyst, one case was diagnosed as bilateral sacroiliitis while the last one was iliacus abscess.

\section{Conclusion}

Magnetic resonance is the best imaging modality to assess hip joint in non-traumatic cases. It has a great ability to diagnose disorders of bone, cartilage, ligaments, muscles and soft tissue. MRI can also detect joint effusion and bone marrow edema.

\section{References}

1. Battaglia P.J., D'Anglo K., Kettner N.W. Posterior, Lateral, and Anterior Hip Pain Due to Musculoskeletal Origin: A Narrative Literature Review of History, Physical Examination, and Diagnostic Imaging. Journal of chiropractic medicine,2016;15(4):281-293.

2. Reddy K.V., Kapoor A. MRI evaluation of non-traumatic hip pain. journal of medical science and clinical research,2017; 5(3):19090-19101.

3. Drar H.A.A, Mohammed B.A.D, Ali Z.A.M. The role of MRI in the evaluation of painful hip joint (MRI of hip joint).International Journal of Medical Imaging,2014;2(3): 77-82.

4. Kalekar T., Shriramwar P. Role of magnetic resonance imaging findings in evaluation of painful hip joint. International Journal of Medical and Health Research, 2017;3(7):105-111.

5. Omar I.M., Blount K.J. Magnetic Resonance Imaging of the hip. Topics in magnetic resonance imaging,2015;24(4):81-165.

6. Gold S.L., Burge A.J., Potter H.G. MRI of hip cartilage: joint morphology, structure, and composition. ClinOrthopRelat Res,2012;470:33213331. 
SOHAG MEDICAL JOURNAL

Vol. 23 No.2Apr 2019
Role of Magnetic Resonance Imaging

Mariam T. Thabit.et al
7. HayemG(2001):Hip pain: Diagnostic orientation. Rev. Prat.,51(13): 14991504.

8. Horia B. , Valentin C, Mihaela D, 2009. Avascular necrosis of the femoral head, A Journal of Clinical Medicine, Volume 4 No.1.

9. Boehm H and Link T, 2004. Bone imaging: traditional techniques and their interpretation. Curr. Osteoporos. Rep. Jun; 2(2): 41-46.

10.TusharKalekar, PoojaShriramwar, 2017. Role of magnetic resonance imaging findings in evaluation of painful hip joint. International Journal of Medical and Health Research; 3(7):105-111

11.David $\mathrm{W}$, William $\mathrm{J}$ and James $\mathrm{M}$, 2004.TheHip.In Diagnostic Imaging
Orthopedics. 1st edition, edited by David, W.; Phillip, F.J.; Miriam, A.; et al., A Medical Reference Publishing Company, Canada, Section 4; PP: 2-98.

12. HayamAbdElmonsifAbdElatifDrar, BasmaAbdElmoneimDessouky Mohammed, ZeinabAbdElaziz Mohammed Ali, 2014. The role of MRI in the evaluation of painful hip joint (MRI of hip joint). International Journal of Medical Imaging. 2(3):77-82.

13. Quinn S. and Carthy J. Prospective evaluation of patients with suspected hip fracture and indeterminate radiographs: Use of T1 weighted MR images. 2002; Radiology, 187:469-471. 